\title{
CONTROVÉRSIAS HISTÓRICAS EM TORNO À IDEIA DE NATUREZA: ATIVIDADES COM IMAGENS
}

\begin{abstract}
HISTORICAL CONTROVERSIES ABOUT THE IDEA OF NATURE: ACTIVITIES WITH IMAGES

ABSTRACT: This paper aims to discuss Nature views of high school students of a public Brazilian school during their Physics classes. These classes focused on History and Philosophy of Science. All the activities were associated with historical paintings or photographs made by the students about their perspective in nature. Four activities took place in two different groups of students during their Physics class. The results of the activities were analysed by Peircean Semiotics and showed a more elaborate view of Nature during the activities.

Keywords: History and Phylosophy of Science. History of the Idea of Nature. Image.

RESUMO: O presente artigo apresenta as discussões sobre as ideias Ensino Médio de um colégio da rede pública federal. Nas duas turmas estudadas, as aulas tiveram o enfoque histórico-filosófico e foram pelos prórios alunos. Foram realizadas e analisadas quatro atividades utilizando essas imagens. As produções dos alunos foram examinadas de acordo com a semiótica peirciana. Os resultados apontam que as tendências, ao representar natureza, foram modificadas ao longo do ao longo do trabalho.

Palavras-chave: História e Filosofia da Ciência. História da ideia de natureza. Imagem.
\end{abstract}

DOI - http://dx.doi.org/10.1590/1983-21172014160207
Luciana Fiúza*

Andreia Guerra**
*Graduada em licenciatura e Doutoranda do Programa de PósGraduação em Ciência Tecnologia e Educação no CEFET-RJ.

E-mail: luciana_fiuza@hotmail.com

* * Mestra em Difusão de Ciência e Tecnologia na Engenharia de Produção pela Universidade Federal do Río de Janeiro (UFRJ). Doutora em História e Filosofia da Ciência na Engenharia de Produção pela Universidade Federal do Rio de Janeiro (UFRJ). Professora pesquisadora do Centro Federal de Educação Tecnológica de Celso Suckow da Fonseca-CEFET-RJ. E-mail: aguerra@tekne.pro.br bacharelado em Biologia pela UERJ. 


\section{INTRODUÇÃO}

O ensino de ciências na educação básica deve proporcionar, mais que o acúmulo de conteúdos formais, a reflexão e a conexão de informações a fim de que os alunos possam definir seus próprios posicionamentos a partir de argumentos formulados por eles mesmos (ALLCHIN, 2004). Um dos caminhos apontados pela pesquisa em ensino para alcançar o objetivo destacado é a abordagem histórico-filosófica (BRAGA et al., 2012; FORATO et al., 2012).

A pretensão de um ensino focado em uma abordagem histórico-filosófica é promover um entendimento mais aprofundado do conteúdo estudado, incentivar o interesse pela ciência e oportunizar o aprofundamento nos fundamentos de Natureza da Ciência (ALLCHIN, 2004; MCCOMAS, 2008). A ciência é apresentada como um processo de construção humana, um processo histórico, social e cultural, e está envolvida nos debates que concernem à sociedade do seu tempo, não sendo neutra nas observações dos fenômenos naturais (MCCOMAS, 2008; FORATO et al., 2012).

Muitas pesquisas foram desenvolvidas com o intuito de discutir os caminhos a serem trilhados para a construção de aulas de ciências numa abordagem histórico-filosófica (BRAGA et al., 2010; FORATO et al., 2012). Uma das possibilidades apontadas por essa abordagem é o uso de controvérsias históricas. $\mathrm{O}$ trabalho com essas controvérsias contribui com uma visão diferenciada de ciência e tecnologia por parte dos alunos, uma vez que ajuda a problematizar ideias de neutralidade, objetividade, verdades inquestionáveis e imutáveis do pensamento científico (RAMOS ; SILVA, 2007; McCOMAS, 2008).

Essas considerações impulsionaram a construção de uma pesquisa com o intuito de trazer subsídios para a discussão em torno do potencial do trabalho com controvérsias históricas em aulas de ciências.

Com vistas a delimitar o objeto de pesquisa, foram selecionadas questões acerca da ideia de natureza. O que é natureza e qual o papel do homem, se pertencente ou observador destacado, é a questão central da controvérsia aqui debatida. É importante destacar que a escolha dessa temática deve-se ao fato de ela estar diretamente ligada a diversas áreas do conhecimento e de ter influenciado ações e gerado consequências no planeta.

Nesse sentido, ainda que pareça apenas recente a necessidade de repensar a relação entre homem e natureza, como se houvesse um conceito já convencionado a ser questionado, esse debate não é estritamente atual. O conceito do que vem a ser natureza tem sido debatido ao longo da história, sob prismas e interpretações construídas e reconstruídas, com sentidos diversificados e controversos. O modo como nos relacionamos e enxergamos a natureza, hoje, é fruto do contexto histórico. As formas de compreender o que é natureza mudaram e se transformaram muito ao longo do tempo, sem nunca deixarem de existir controvérsias e debates a respeito do tema (LENOBLE, 1990; GALIMBETI, 2006). 
As diversas compreensões em torno à ideia de natureza podem ser estudadas ao longo do tempo de diversas formas. Podemos começar, por exemplo, com a visão de natureza idealizada do naturalismo inglês do século XVII, passando pela visão iluminista de uma natureza controlada pela razão, assim como pelas novas sensibilidades burguesas e suas necessidades de recursos e matérias-primas no século XVIII. Também podemos abordar o romantismo e a naturphilosophie dos séculos XVIII e XIX, que viam a natureza como um ser orgânico em harmonia. Além disso, podemos falar sobre o imaginário exótico que existe em torno à natureza da América. Ao percorrer essas diversas sensibilidades e paisagens produzidas historicamente, poderemos encontrar as várias ideias de natureza (CANEVA, 1997; CAMPONOGARA et al., 2007).

Entre as possíveis controvérsias estabelecidas em torno à relação homem versus natureza, escolhemos trabalhar com as questões debatidas no início do século XIX. Essa escolha ocorreu em função da opção por realizar uma pesquisa de cunho empírico e pela delimitação do objeto de pesquisa, como discutiremos a seguir.

\section{0 CONTEXTO DA PESQUISA}

Os resultados de uma pesquisa prévia (autores, 2011) indicaram que o tema natureza é reconhecido por professores de Biologia, Química e Física como pertencentes às suas disciplinas, mas apenas os de Biologia se dedicam a discutir o assunto. Desse grupo, os professores de Física foram aqueles que se mostraram mais avessos a trabalhar o tema em sala de aula, apesar de reconhecerem a relevância de tal assunto. Esse resultado, aliado ao fato de o grupo de pesquisa que desenvolveu esse trabalho ser formado tanto por professores de Física quanto de Biologia, levounos a desenvolver a pesquisa em aulas de Física do Ensino Médio. A escolha desse universo está também relacionada ao fato de que visões de natureza influenciam todo o conteúdo a ser transmitido e estão diretamente conectadas ao momento histórico em que o conteúdo foi desenvolvido como saber. Em aulas de Biologia, disciplina que comumente trabalha o tema natureza, algumas respostas ou linhas de pensamento são consideradas pelos alunos como as desejadas pelo professor, ou seja, representam a resposta certa que os alunos tanto buscam. Trazer esse debate para uma aula de Física poderia permitir um novo olhar para a questão, saindo do discurso pronto que os alunos poderiam julgar como o mais correto.

Dessa maneira, realizamos o presente trabalho dentro do curso de Física. Porém, o fato de as controvérsias históricas serem o tema central da pesquisa levou-nos a desenvolver a pesquisa em um curso em que a abordagem histórico-filosófica fosse a privilegiada. Isso nos encaminhou ao trabalho com duas turmas de terceiro ano do Ensino Médio em uma escola da rede federal de ensino. O assunto estudado nas aulas de Física dessas turmas era o eletromagnetismo, delimitando o estudo da controvérsia homem versus natureza nas primeiras décadas do século XIX e, mais precisamente, nas primeiras décadas deste século. Isso porque 
a abordagem histórico-filosófica conduzida pelo professor de Física situava-se nas primeiras décadas do século XIX, em torno à controvérsia histórica estabelecida com os trabalhos de Oersted, Biot, Ampère e Faraday. Assim, o trabalho sobre as controvérsias em torno à ideia de natureza foi inserido durante o debate histórico-filosófico no qual estavam sendo apresentadas as controvérsias relacionadas aos resultados do experimento de Oersted.

Dentro desse cenário, passamos a construir caminhos para responder a pergunta central dessa pesquisa: quais elementos em torno à controvérsia homem versus natureza são identificados junto aos alunos num curso de Física que tem por eixo condutor a História e a Filosofia da Ciência? destaquei a pergunta com a grafia em itálico

O problema dessa pesquisa encaminhava a um trabalho empírico desenvolvido numa sala de aula. Com vistas a superar os obstáculos referentes ao tratamento historiográfico e ao tempo didático (FORATO et al., 2012), optou-se por trabalhar a controvérsia selecionada a partir do uso de imagens como fontes primárias. Desse modo, não foram usadas apenas imagens produzidas na época que dialogassem com as diferentes ideias de natureza, mas também imagens com as quais os alunos pudessem se relacionar de maneira crítica e contextualizada. Por esses motivos, foram escolhidas paisagens da cidade onde se situava a escola na qual a pesquisa foi desenvolvida: o Rio de Janeiro. Esperava-se que, com a similaridade geográfica entre as imagens e a realidade do aluno, fosse gerada uma referência de proximidade. A ideia era que o aluno discutisse a controvérsia histórica da relação homem versus natureza com uma referência concreta e presente. Com isso, a intenção era trazer um novo elemento de urgência e proximidade para uma discussão que parecia tão distante e etérea.

\section{AS IMAGENS HISTÓRICAS COMO FONTES PRIMÁRIAS}

Ao trabalhar as paisagens históricas como fontes primárias é relevante destacar que toda imagem é produzida com um objetivo. Dessa forma, é preciso se atentar, levando em consideração o contexto histórico e cultural, para o que as imagens deixam transparecer e para o que omitem, observando, inclusive, seu autor, sua presença no cenário que retrata e sua percepção e interesses (SANTAELLA, 2005; COSTA, 2006; REIS et al., 2006; TUCKER, 2006; BURKE, 2009; ROUILLÉ, 2009).

Toda imagem é produzida com um objetivo, e essa é uma das fundamentais perguntas a se fazer ao documento (BURKE, 2009). A análise de uma imagem como referencial histórico é indicada como uma oportunidade que, associada aos documentos escritos, pode contribuir para o melhor entendimento das questões do passado (COSTA, 2006; TUCKER, 2006).

No século XIX, ocorreu um grande aumento na produção e nos registros de ilustrações de plantas, animais e paisagens através de imagens vistas como realistas, produzidas por artistas com formação específica para tanto (BURKE, 2004; 
COSTA, 2006). A imagem na divulgação científica tem significado importante para esse século, em que não apenas se imitava ou copiava a natureza, mas se selecionava o que era ou não merecedor de ser mostrado, o que deveria ou não ser relevante. Era mais que um desenho de valor estético apenas, era uma evidência da realidade tal como entendida pelo autor na sua época (BURKE, 2004; COSTA, 2006; TUCKER, 2006).

Os artistas profissionais pintavam não apenas a partir de seus interesses estéticos. Eles eram formados em escolas especializadas, influenciados pelas questões acadêmicas, pelos debates filosóficos, pelas controvérsias, etc. Além dessas questões, os artistas se preocupavam com os consumidores de suas imagens que eram, afinal de contas, seus financiadores. Para esses consumidores, as imagens dos viajantes tinham valor de "testemunhas virtuais" de lugares que não eram acessíveis para todos (BURKE, 2004; MARTINS, 2004; COSTA, 2006). Um dos lugares mais visitados pelos artistas era o Rio de Janeiro, não apenas por ser um porto importante, mas porque o mundo voltava os olhos para a nova capital do reino português e suas belezas pitorescas (COSTA, 2006).

Nesta pesquisa foram abordados dois tipos de olhares para a paisagem do Rio de Janeiro do século XIX: a britânica e a francesa. Por motivos históricos, filosóficos e políticos, a chegada e a relação desses artistas com essa paisagem eram completamente diferentes. Todo esse contexto influencia o olhar dos viajantes, inclusive a ideia de natureza que que eles pretendiam retratar. Enquanto os britânicos eram viajantes de um império rico que tinha Portugal como seu aliado, crescendo científica e tecnologicamente, os franceses haviam acabado de perder as guerras napoleônicas. Os britânicos passaram por aqui sem se fixar, enquanto os franceses não só permaneceram por muitos anos Qual escola? No Rio de Janeiro? (MARTINS, 2004; SCHWARCZ, 2008).

\section{4- CAMINHOS METODOLÓGICOS}

O enfoque da investigação foi qualitativo, com o objetivo de usar como referência estudos mais aprofundados que nos auxiliassem a responder a pergunta da pesquisa. O principal interesse deste trabalho é o processo e a forma como os alunos evoluíram durante as atividades (BOGDAN \& BIKLEN, 1994; FLICK, 2009).

A pesquisa foi realizada em uma escola federal da rede pública que se caracteriza por ter a opção de ensino técnico no contraturno. Há, no mesmo espaço físico, cursos de graduação e pós-graduação. Os alunos participam de processo de seleção para entrar no primeiro ano do Ensino Médio e optam por um dos cursos técnicos ofertados na instituição.

A pesquisa foi aplicada em duas turmas: "A", com um total de 38 alunos; e "B", com 33. A turma A, por questões circunstanciais, teve professores de Física, no primeiro e no segundo ano, que desenvolveram os conteúdos a partir de uma abordagem histórico-filosófica. A turma B teve, ao longo dos dois anos, cursos em 
que o enfoque estava nos produtos da ciência e não em seu processo de construção. Ambas as turmas cursavam Ensino Médio de manhã e curso técnico à tarde. Além disso, ambas cursaram, no terceiro ano, o mesmo conteúdo trabalhado com enfoque histórico-filosófico com a mesma professora. A maioria dos alunos, apesar do curso técnico, desejava, ao final do Ensino Médio, prestar concurso para ingresso em universidades públicas do Brasil.

As aulas nas quais o trabalho foi realizado eram de Física, cujo conteúdo em questão era o eletromagnetismo. Dentro da discussão histórica do desenvolvimento do eletromagnetismo na primeira metade do século XIX, apresentamos a controvérsia entre a naturphilosophie e o mecanicismo, com vistas a discutir com os alunos que a ciência é uma construção humana e não é realizada através de descobertas ocasionais e descontextualizadas, que nenhuma teoria é neutra, livre de pressuposições, sendo as teorias científicas verdades contextualizadas que se modificam temporalmente (BRAGA et al., 2012). Dessa forma, a apresentação do experimento de Oersted visou discutir a não aleatoriedade da evidência da relação entre eletricidade e magnetismo, evidenciada naquela experiência, e o fato de o trabalho desse filósofo natural, assim como os daqueles que trabalharam sobre o tema após a divulgação dos resultados desse experimento, estar imerso em questões filosóficas, que permeavam visões distintas de natureza (CANEVA, 1997).

\section{O desenvolvimento das atividades geradoras de dados para a pesquisa}

Quatro atividades específicas foram planejadas com o intuito de colher dados para esta pesquisa. Ao fim da atividade 3, o colégio entrou em greve. Isso, de certa maneira, prejudicou a pesquisa, que contava com o desencadeamento de ideias dos alunos e não poderia esperar os meses de greve para ser finalizada. Os alunos não poderiam ser obrigados a completar a atividade 4 durante a greve. A solução encontrada foi enviar por e-mail o estudo dirigido da atividade 4 e os alunos interessados poderiam responder digitalmente. Os que completaram todas as atividades, incluindo a desenvolvida no período de greve, foram os que tiveram os trabalhos analisados nesta pesquisa. $\mathrm{Na}$ análise, os alunos foram identificados como A1, A2 etc.

A primeira das atividades foi desenvolvida após três meses de aula. $\mathrm{Na}$ quele momento, a professora já havia apresentado o experimento de Oersted e discutido as controvérsias em torno à sua interpretação, enfocando nas questões filosóficas em torno ao debate naturphilosophie versus mecanicismo (CANEVA, 1997; BRAGA et al., 2012). Nas aulas imediatamente anteriores ao desenvolvimento da atividade 1, além do experimento de Oersted, a professora discutiu: a resposta de Jean Baptiste Biot aos resultados do experimento, a posição de André Marie Ampère, os experimentos desenvolvidos por ele e a teoria criada para interpretar os resultados obtidos, o diálogo entre Faraday e Ampère e os trabalhos a respeito da indução eletromagnética.

As duas primeiras atividades tiveram o propósito de apresentar aos alunos questões que os fizessem refletir e debater sobre a relação homem e Natureza. No 
primeiro momento da atividade, pedimos aos alunos que apresentassem palavras que os remetessem ao que era natureza. Conforme os alunos falavam, a professora anotava as palavras no quadro branco, de forma a ficarem visíveis a todos. A turma, em conjunto, selecionou quinze das palavras citadas, com vistas a compor uma lista, que denominamos: brainstorm. A escolha das palavras ocorreu a partir de um debate entre todos os componentes da turma, de forma que as palavras listadas expressavam, de certa forma, o resultado desse primeiro debate. A lista formada serviu de base para a atividade 2 .

$\mathrm{Na}$ aula seguinte, foi proposta aos alunos a atividade 2. Nessa atividade, os alunos deveriam compor um cartaz com imagens e palavras de forma que o resultado final expressasse como o grupo percebia a relação homem versus natureza. A atividade 2 foi desenvolvida em grupos de 3 a 5 alunos. De forma a respeitar os pressupostos dessa pesquisa, cada grupo recebeu as cinco imagens históricas ${ }^{1}$, selecionadas para a pesquisa, com paisagens do Rio de Janeiro do século XIX impressas em folhas comuns de tamanho A4. As imagens históricas escolhidas, 1, 3, 4 e 5, apresentadas nos resultados, foram retiradas do livro de Ermakoff (2011) e a imagem 2 do livro de Schwarcz (2008).

Quanto à escolha das imagens, foram selecionados dois pintores ingleses e dois franceses, cuja história estivesse ligada com o desenvolvimento científico ou tecnológico do Rio de Janeiro. Os dois ingleses escolhidos, Augustus Earle e Conrad Martens, participaram na famosa expedição do Beagle, que contava com a presença de Darwin; e, quanto aos franceses, Nicolas-Antoine Taunay foi um dos fundadores da Escola de Belas Artes do Rio de Janeiro e Victor Frond ajudou a introduzir a fotografia e a divulgar a cidade. Todas as imagens selecionadas tinham presença de elementos considerados mais naturais (árvores, céu, água etc), assim como a presença de humanos e suas construções. Não foi realizado nenhum tipo de proporção ou correlação das imagens. Elas deveriam apenas ser de autores relevantes, paisagísticas, e contar com os elementos homem e natureza (SCHWARCZ, 2008; ERMAKOFF, 2011).

As imagens foram entregues aos alunos com a legenda correspondente, mas sem numeração e nenhum tipo de ordem. Foram, também, distribuídas uma folha de papel pardo grande, caneta da marca "pilot" e fita dupla face. Para completar a atividade, cada grupo deveria construir um cartaz usando as imagens e as palavras do brainstorm, de forma que o resultado final expressasse os resultados da discussão do grupo sobre a relação homem versus natureza. O grupo era livre para acrescentar outras palavras que achasse pertinentes e não era obrigado a usar todas as palavras expostas, apenas as que considerasse importantes.

Após a confecção dos cartazes, os grupos foram convidados a apresentar seu trabalho para toda a turma, o que encerrava a atividade 2. Cada grupo selecionou um relator que explicou as associações entre as imagens e as palavras escolhidas para compor os cartazes. O desenvolvimento dessa apresentação foi registrado em vídeo. Os alunos estavam cientes da câmera mantida no fundo da sala em um tripé durante os dois dias de apresentação dos grupos. Foi explicado a eles que as imagens 
coletadas no vídeo teriam intuito apenas de permitir a retomada de falas para as atividades seguintes. Não existiria nenhuma forma de divulgação posterior das imagens. A câmera foi mantida ligada do começo ao fim da aula, enquanto as professoras participavam dos debates. Durante as apresentações, foi dada ao restante da turma oportunidade de debater com os alunos que apresentavam seus cartazes.

Observando os principais pontos levantados por cada grupo sobre o que as imagens e palavras remetiam a eles, e tendo em mente as controvérsias históricas sobre a relação homem versus natureza do século XIX, as professoras formularam uma ou mais sentenças para cada grupo. Tais sentenças, construídas após a análise dos dados coletados com as atividades 1 e 2, compuseram a atividade 3 .

Para desenvolver a terceira atividade, cada grupo recebeu a sentença construída para seu grupo, que tinha o pressuposto de questionar ou reafirmar algo dito em sala de aula e que estava contextualizado nas controvérsias do século XIX. Cada aluno, inspirado pela sentença correspondente ao seu grupo, individualmente, teria que fotografar uma imagem do seu cotidiano e escrever um texto explicando a imagem, a fim de argumentar seu posicionamento em relação à sentença, ou seja, o texto e a foto deveriam expressar sua concordânciaa ou discordância com a sentença. Os alunos tiveram cerca de uma semana para completar a atividade. Após a entrega por e-mail da imagem com o texto, estava encerrada a atividade 3.

A proposta da atividade 3 era aprofundar as reflexões levantadas a partir do debate com as imagens históricas. Agora, no lugar de observar e pensar sobre uma imagem, o aluno deveria formular uma imagem e dali explicar quais eram as informações que pretendia transmitir com elas, a fim de que isso o incentivasse a refletir sobre o lugar onde vive.

Ao pedir que fotografassem imagens de natureza no seu cotidiano, pretendíamos induzir os alunos a considerarem, ao menos durante a atividade, a natureza como presente em seu dia a dia. Dessa maneira, o olhar dos estudantes seria direcionado de forma que a partir da natureza fotografada pudessem ser aprofundadas questões qualitativas a respeito do ambiente em eles estão inseridos.

Para finalizar o trabalho, foi proposta a atividade 4. O planejamento dessa atividade teve interferência da greve dos docentes da escola em que a pesquisa foi desenvolvida. Os alunos não podiam realizá-la na escola na presença das professoras. Assim, propôs-se um estudo dirigido. Os alunos receberam por e-mail um texto histórico. Esse texto apresentava questões histórico-filosóficas discutidas nas aulas de eletromagnetismo, principalmente as referentes à divulgação e aceitação do experimento de Oersted, e relacionava esse contexto histórico-filosófico às imagens históricas usadas na atividade 2. Dessa forma, buscava-se ressaltar o contexto histórico em que os pintores as produziram e as questões em torno à controvérsia homem versus natureza daquele contexto. Ao texto seguiam quatro perguntas, sendo três delas a respeito do texto e a última na qual o aluno deveria falar das controvérsias da relação homem versus natureza percebidas no mundo atual. 


\section{CRITÉRIOS DE ANÁLISE}

A análise dos dados coletados a partir das quatro atividades foi baseada na teoria da semiótica peirciana (SANTAELLA, 2004; SANTAELLA, 2005; PEIRCE, 2010; SANTAELLA, 2012; JAPPY, 2013). Para tanto, as atividades individuais dos alunos, a 3 e a 4, foram impressas e acondicionadas em um fichário. Para cada aluno, foi produzida uma ficha com critérios de análise que visavam responder a questão central do trabalho.

Dentro da lógica peirciana, vivemos em um mundo onde nossa compreensão da realidade é sempre mediada por signos. Peirce postulou que todo pensamento se dá em signos, e não há pensamento sem signos. Qualquer mediador de uma informação que atinja um significado para um seré um signo (SANTAELLA, 2005; JAPPY, 2013). Os signos podem ser de três tipos: qualisignos (primeiridade); sinsignos (secundidade); legisignos (terceiridade). Os qualisignos representam as qualidades das coisas, as características. Os sinsignos indicam a materialidade das coisas, a existência substantiva. Os legisignos são as leis, convenções sociais e acordos. Esse terceiro tipo de signo refere-se às convenções que um grupo de pessoas de uma determinada época e lugar reconhecem como significado comum. Nenhum signo se resume a um dos três tipos, em geral ele é uma mistura dos três. O interpretante, ao ler o signo, vai mediar, de acordo com seu conhecimento e suas escolhas, quais aspectos serão mais destacados (SANTAELLA, 2005; 2012).

Analisando os resultados das atividades 3 e 4 através de uma vertente semiótica, podemos perceber alguns padrões nos tipos de signo abordados pelos alunos, tanto para a imagem quanto para o texto. Essa análise prévia do material permitiu-nos proceder a análise final dos resultados a partir dos três signos, com os seguintes critérios:

- Qualisignos: alunos utilizavam nas fotos ou nos textos argumentos que valorizavam aspectos apenas qualitativos, como: beleza, harmonia, qualidade de vida, equilibrio, preservação. As imagens associadas foram denominadas icones.

- Sinsigno: os alunos apontavam exemplos do que consideravam real, verdadeiro, nas fotos e textos. Os textos eram sempre propostas de ações, soluções ambientais, listagem de posturas que as pessoas deveriam tomar contra e a favor de questões ambientais, sempre de cunho ético. As imagens associadas foram denominadas indices.

- Legisigno: nesse tipo de signo as imagens eram simbólicas, usando símbolos convencionais e socialmente conhecidos, como, por exemplo, o símbolo de reciclável em uma embalagem. Já no texto os alunos utilizavam o discurso legitimado por outros como justificativas e fatos científicos, políticos e de Organizações não governamentais (ONGs) como "Greenpeace" e outras autoridades ambientalistas. 
Nem sempre um trabalho cuja imagem fosse classificada como um tipo teria o texto classificado do mesmo modo. Algumas vezes, por exemplo, um texto predominantemente legisigno, baseado em legitimação de autoridades científicas, era acompanhado de uma imagem índice que previa uma ponte direto para a realidade, com intenção de "provar" a argumentação. No entanto, esse não é um padrão, alguns alunos foram coerentes entre texto e imagem no que se refere à predominância dos tipos de signos.

Dentro da proposta do trabalho, as palavras geradas nas primeiras atividades foram consideradas objeto na atividade 3 e capazes de gerar os signos: a fotografia e o texto associado. Era esperada coerência entre as atividades e uma defesa da ideia de natureza do aluno, no entanto, alguns deles mudaram seu posicionamento radicalmente durante as atividades, não tendo o mesmo ponto de vista que demonstraram no início. É importante destacar que com esses alunos foi possível perceber a maior variedade de tipos de signos no mesmo trabalho. Isso pode apontar que para esses alunos o assunto ainda está aberto e sendo rediscutido durante e depois das atividades. A descrição completa dos resultados analisados encontra-se na seção seguinte.

\section{6- RESULTADOS E DISCUSSÃO}

A ideia de Natureza como um signo é de alta complexidade, com muitos objetos e interpretantes diferentes. Não foi ambição da presente análise compreender em pormenores dos interpretantes gerados pelos alunos, apenas classificar a variedade de signos que traziam para a sala de aula em relação ao tema apresentado. O foco foi o processo, e, assim, procurou-se investigar quais elementos em torno a essa relação foram identificados em um trabalho que privilegiou trabalhar a História e a Filosofia da Ciência associada a princípios de semiotica peirciana.

\section{1- Resultados das atividades 1 e 2}

Os alunos puderam escolher 15 palavras na atividade 1. Nessa lista, as palavras puderam ser identificadas nos três tipos de signos: qualisigno, sinsigno ou legisigno. As palavras verde e vida, que apareceram em ambas as turmas, foram identificadas como qualisignos. Elas designam qualidades do que é natureza para os alunos. A outra palavra foi "animais", que apesar de ser considerada sinsigno, corrobora com a questão de vida como sinônimo de natureza. Como resultado da análise, percebe-se que na primeira atividade, a turma B utilizou mais palavras classificadas como legisignos (sete), relacionadas a ciências e ao ambientalismo, e apenas três usaram sinsignos e quatro, qualisignos.

A turma A valorizou, por sua vez, mais qualidades e adjetivos que revelam a natureza como "paz", "vastidão", "delicadeza", "verde”. A turma A selecionou oito qualisignos, quatro sinsignos e três legisignos. 
Em relação às palavras usadas para falar de objetos concretos presentes na natureza, os sinsignos, ambas as turmas usaram aproximadamente o mesmo número de palavras (quatro na turma $\mathrm{A}$ e três na turma $\mathrm{B}$ ).

$\mathrm{Na}$ segunda atividade, com os cartazes e imagens históricas, os alunos acrescentaram algumas palavras. Isso mostra que a atividade com imagens, a atividade 2 , acrescentou novos aspectos relativos à ideia de natureza em relação à primeira atividade, o brainstorm. Os três tipos de signo apareceram em todas as palavras escolhidas pelos alunos.

O termo "vida" é repetido em uma frequência de 41 vezes, considerando todas as imagens, todos os grupos, em ambas as turmas. O segundo termo mais citado é "verde”, que aparece 19 vezes seguido por “água”, que é citada 13 vezes. Fica evidente a importância da palavra vida, mas não apenas por isso.

Observando o padrão das frequências da palavra "vida" nas duas turmas, podemos notar que na turma B todos os sete grupos usam a palavra até a imagem 3, a primeira do Martens. Após isso, dois grupos passam a usar a palavra "morte" nas imagens 4 e 5, sendo que um desses grupos, na última imagem, no lugar de "morte" usou a palavra "progresso", no sentido de progresso tecnológico e urbano. Essa escala entre vida e morte, entre natural (vida) em escala até o antrópico (morte) é que determinou a ordem como os alunos organizaram as imagens.

Esse comportamento é relativo a uma tendência de ambas as turmas. Todos os grupos, sem exceção, tenderam a criar uma linha contínua entre as imagens. Uma espécie de história da sucessão ecológica no Rio de Janeiro, indo do mais primitivo, natural, ao mais derivado, antrópico. Literalmente com essas palavras os grupos criaram uma sequência, uma escala, que variava pouco as imagens de lugar, entre Earle e Taunay como primeiro ou segundo, e Frond e a segunda pintura de Martens como quarto e quinto. Normalmente, a primeira pintura de Martens era colocada como equilíbrio entre homem e natureza, mas nem sempre de uma forma positiva.

A ordem na qual a maior parte dos alunos colocou as imagens foi a seguinte:

Imagem 1: Augustus Earle: Vista do Cume do Corcovado - 1822

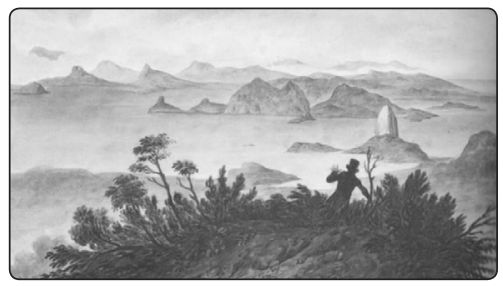


Imagem 2: Nicolas-Antoine Taunay: Cascatinha da Tijuca - 1816

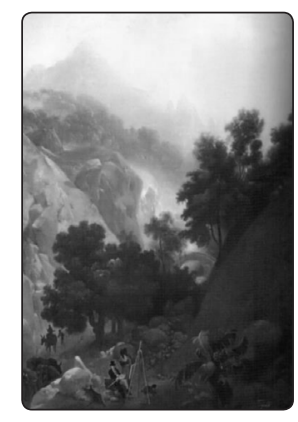

Imagem 3: Conrad Martens: Botafogo, Rio de Janeiro - 1833

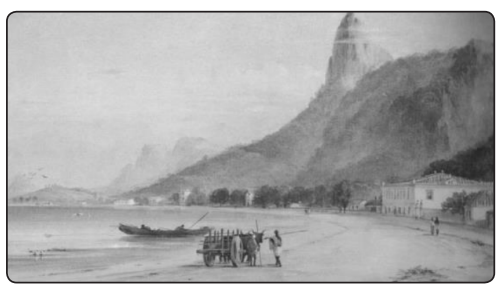

Imagem 4: Conrad Martens: A Capela Real \& um lado da Grande Praça - 1833

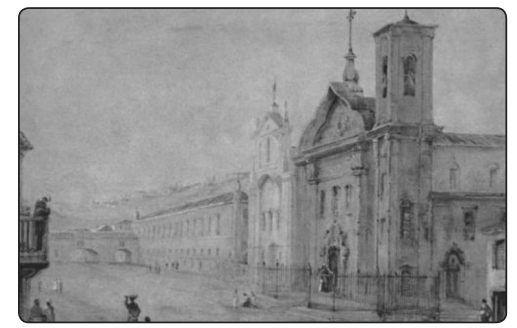

Imagem 5: Victor Frond: Panorama do Rio de Janeiro - 1858

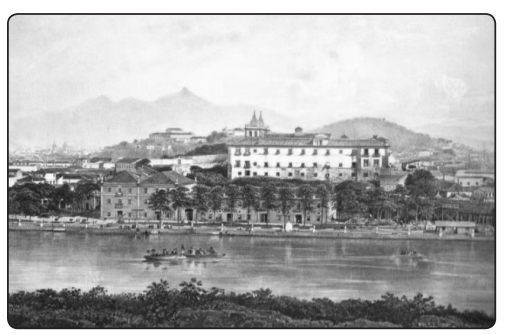

Todos os grupos fizeram uma sequência do tipo narrativa. Embora essas narrativas apresentassem diferenças em relação a formato e argumentos, a ideia de se- 
quência foi a mesma. No entanto, todas as imagens são próximas no tempo, não existe diferença significativa de períodos para pensar em sucessão e degradação ambiental. Em nenhum momento foi pedido que relacionassem as palavras entre si, apenas que relacionassem as palavras às imagens. Todas as imagens foram selecionadas de forma a conter figuras humanas ou construções, e também elementos naturais, como água, vegetação, céu, etc. Elas foram selecionadas em função do tema trabalhado na aula de Física e por corresponderem ao mesmo período (1816-1858). Foram escolhidas paisagens que representavam pontos conhecidos da cidade, por pintores diferentes, com visões de natureza diferentes. A organização das imagens em sequência por parte dos alunos foi inesperada e, por isso mesmo, é considerada um resultado relevante.

A turma B, durante os debates, discutia mais sobre qual seria o futuro da natureza, problematizando se ela seria destruída pelo homem ou não. Nessa turma, os alunos se dividiram entre os que diziam que a natureza iria se transformar, recuperar e continuaria sempre existindo, e os que diziam que o homem iria matar tudo e que teriam que mudar de planeta ou que morreriam. O debate foi iniciado com o aluno A3 do grupo G1, na turma B, afirmando: "ou a sociedade e o consumo como a gente conhece mudam drasticamente ou não existirá mais natureza". A partir dessa afirmativa, todos os alunos se posicionaram em relação a esse argumento, inclusive nas atividades 3 e 4, como será discutido adiante.

A turma A também discutiu o futuro da natureza e do homem, mas sob outro ângulo. Preocupavam-se mais com a tecnologia, com os direitos do homem, se existiria alguma forma de reverter os impactos causados pelo homem ou conviver com esses impactos no futuro e como isso seria possível. Os alunos dessa turma buscaram mais termos descritivos e debateram fatos pontuais ou exemplos restritos. Esses alunos, de uma forma geral, se mostraram mais críticos com as posturas de ambientalistas e de autoridades que discutem essas questões.

Gráfico 1: As barras mostram o número de palavras de cada tipo de signo em cada uma das imagens históricas para as turmas A e B

Turmas A

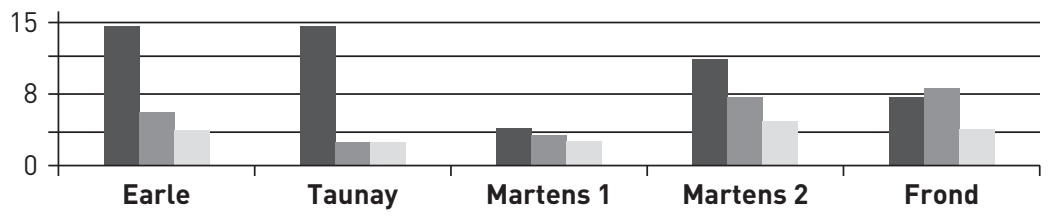

Turmas B

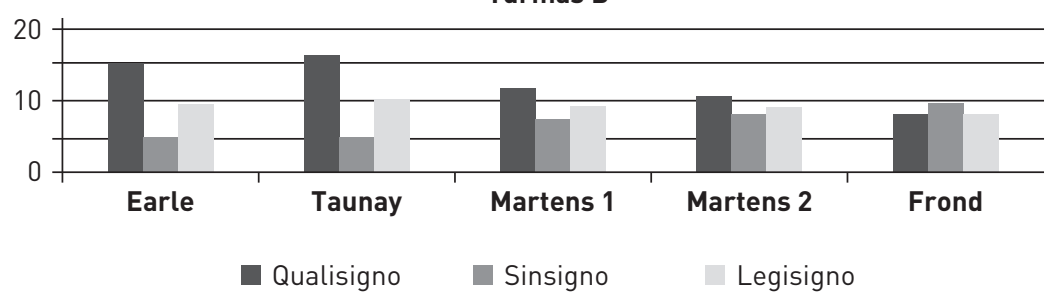


Nos gráficos acima, é possível observar quantas palavras de cada tipo foram usadas pelos grupos, por imagem histórica, incluindo a frequência de repetições. Ao confrontar esses dados com a organização das imagens construídas pelos alunos, que foi feita a partir da imagem considerada mais natural para a mais antropizada, percebe-se que: a frequência de qualisignos decresce enquanto a dos sinsignos cresce. Esse resultado aponta o entendimento dos alunos sobre o que vem a ser mundo natural e vivo, considerado de uma forma mais qualitativa, icônica, enquanto do urbano, antrópico, como mais concreto, indicial, cotidiano. Assim, eles representam dois polos separados em que um é o extremo extremo do outro, e o urbano seria o derivado e aquele em que os alunos reconhecem como apontando o real.

É importante destacar que a imagem 5, cujo autor é Frond, se baseia em um daguerreótipo, um tipo primitivo de fotografia. Embora em seus argumentos os alunos apontem a imagem como revelando "morte", "urbano" e sendo o extremo oposto a "vida" ou "natural", em ambas as turmas eles usaram mais palavras do tipo sinsigno. Esse fato pode ter uma correspondência com o fato de a imagem 5 ser uma fotografia e não uma pintura. As fotografias são, geralmente, índices que apontam para uma realidade de forma muito mais precisa que os quadros a óleo dos outros pintores que são, por sua vez, mais icônicos - qualisigno. No entanto, nenhum aluno expressou perceber que se tratava de uma fotografia, até porque a imagem a eles apresentada foi litografada e aquarelada à mão na época. $\mathrm{Na}$ turma A, as professoras, ao final do debate, falaram sobre essa característica da imagem do Frond como uma curiosidade e os alunos se mostraram surpresos por ser uma foto e não uma pintura (SANTAELLA, 2005; ERMAKOFF, 2011).

A turma A descrevia natureza com qualidades, destacando o que diferencia a natureza do que é humano. Desde o princípio, essa turma manifestou preocupação em delimitar claramente as fronteiras entre o que era humano e o que era natural, com forte tendência de discurso descritivo. A turma B, por outro lado, procurou referenciar suas análises ao que é legitimado cientificamente. Essa característica se fez presente não apenas nas palavras escolhidas, mas também nos discursos dos alunos, registrados ao longo da construção dos cartazes e nos debates oriundos das apresentações dos cartazes.

Embora a preocupação central de ambas as turmas tenha sido o futuro da humanidade e a questão de recursos naturais, a turma A se mostrou mais preocupada com a racionalidade humana. Eles se questionavam se a racionalidade dos homens daria mais direito ou não de explorar o planeta, e se a natureza tenderia ao equilíbrio e extinguiria a humanidade. Já a turma B sugeriu soluções tecnológicas por meio das quais o homem, poderoso e dominador da natureza, abandonaria a Terra e iria para Marte para garantir sua sobrevivência, sem, entretanto, abrir mão da exploração dos recursos naturais.

\section{2- Resultados das atividades 3 e 4}

$\mathrm{Na}$ atividade 3, definimos o objeto a ser fotografado: a cidade do Rio de Janeiro. $\mathrm{O}$ aluno precisava olhar a cidade que mora buscando expressar sua ideia 
de natureza através da expressão fotográfica. A atividade 3, foto e texto produzidos pelos alunos, foi analisada em conjunto com a atividade 4. Foram considerados apenas, para a análise, trabalhos de alunos que tenham completado satisfatoriamente todas as atividades, o que reduziu o número total de alunos.

Para tal, construímos uma ficha para cada aluno. Os critérios para a produção e montagem das fichas foram inspirados no sugerido por Santaella (2012). No que diz respeito à relação palavra e imagem, as opções eram: complementariedade - texto e imagem se complementariam com valores semelhantes para o sentido; dominância - texto ou imagem sobrepor-se-iam; redundância - quando o texto apenas descrevesse a imagem sem nada acrescentar fora da descrição; discrepância - quando o texto e imagem estivessem em completa oposição, um dizendo algo e o outro o oposto. O resultado dessas fichas está apresentado na tabela 1, na qual está relacionado o número de alunos analisados que chegaram até o fim das atividades dentro dos padrões estipulados.

Tabela 3: Análise das atividades 3 e 4

\begin{tabular}{|c|c|c|}
\hline Parâmetro & Turma A & Turma B \\
\hline Total & 16 & 17 \\
\hline \multirow{2}{*}{ Palavra X Imagem } & Complementaridade: 9 & Complementariedade: 12 \\
\hline & Dominância: 7 & Dominância: 5 \\
\hline \multirow{4}{*}{$\begin{array}{c}\text { Como a imagem foi trabalhada pelo } \\
\text { aluno }\end{array}$} & Ícone: 2 & Ícone: 8 \\
\hline & Índice: 8 & Índice: 4 \\
\hline & Símbolo: 2 & Símbolo: 3 \\
\hline & Não definível: 4 & Não definível: 2 \\
\hline \multirow{3}{*}{ Interpretante } & Estético: 3 & Estético: 9 \\
\hline & Ético: 9 & Ético: 3 \\
\hline & Lógico: 5 & Lógico: 5 \\
\hline \multirow{2}{*}{ Reconhece as controvérsias } & Sim: 13 & Sim: 11 \\
\hline & Não: 3 & Não: 2 \\
\hline
\end{tabular}

$\mathrm{Na}$ amostra analisada, apenas foram encontrados os elementos complementariedade e dominância. Nenhum dos trabalhos apresentou relações texto e imagem de modo diferente. No caso da dominância, sempre foi do texto em relação à imagem e nunca o contrário, ou seja, nunca a imagem apareceu como o principal. No total das duas turmas, foram 6 os alunos que consideraram as imagens apenas como ilustrativas. Esses alunos nem citaram as imagens nem as explicaram nos textos construídos, mostrando uma dominância completa. Nesses casos em que o texto sequer fazia menção à imagem correspondente, inviabilizou-se 
a compreensão de qual significado aquele signo tinha para o aluno. Dentro desse perfil temos 4 alunos na turma A e 2 alunos na turma B.

Os outros tipos de signo foram definidos de acordo com o modo como o aluno se referia à imagem ao longo do texto. Se a imagem estava ali por uma qualidade em comum com o texto e com a natureza que referenciava, a classificamos como um ícone. Se apontasse para uma realidade e se fosse um exemplo concreto do argumento, a classificamos como um índice. No caso de símbolos conhecidos, como reciclagem, a imagem foi classificada como um símbolo.

Nem sempre os alunos usavam apenas um tipo de signo ou interpretante, mas foi eleito o tipo preponderante, de acordo com os critérios descritos. Um interpretante estético falaria mais de questões qualitativas de direitos e papéis, de responsabilidades; um interpretante ético, de questões práticas quanto ao meio ambiente e o que o homem deveria fazer; e um interpretante lógico se fundamentaria basicamente no que a ciência e os ambientalistas dizem, sem tomar partidos nem sugerir propostans, apenas legitimaria seu discurso em autoridades.

Nesse ponto, é possível perceber que as tendências das turmas na primeira atividade se modificaram nessa última parte. A turma $\mathrm{A}$, no começo, tinha escolhas mais voltadas a aspectos qualitativos, descritivos, e nessas atividades a tendência se voltou para um sujeito ético e os signos apontavam para uma realidade como índice. Os alunos olharam em volta de si. A turma B, por outro lado, também não manteve a tendência de legisigno baseada apenas no discurso legitimado pela sociedade; eles fizeram trabalhos questionando se a natureza seria capaz de sobreviver ao homem.

Um assunto repetidamente discutido pelos alunos da turma $\mathrm{B}$, nas atividades 2 e 3, foi a questão do domínio do homem sobre a natureza. Tanto nos debates quanto no trabalho escrito a turma se dividiu entre dois grupos. Para o primeiro grupo, a natureza seria superior ao homem e continuaria a existir mesmo que transformada, enquanto o homem padeceria se a continuasse degradando. Já para o segundo grupo, o homem esgotaria os recursos naturais do planeta, exterminando a natureza. Esses 2 grupos se subdividiram. No primeiro grupo, a subdivisão ocorreu entre alunos que defenderam a natureza como vingativa, e que o homem seria extinto de todo modo, e alunos que colocaram o humano como um ser com chance de sobreviver se mudar completamente seu modo de vida. $\mathrm{O}$ segundo grupo se subdividiu entre os que afirmaram que se algumas mudanças no mundo de consumo forem feitas, haverá salvação para a natureza; e os que disseram que os modos de consumo e produção não mudarão e que devemos nos mudar para Marte (nas palavras dos alunos).

Cobern (2000) descreve que essas tendências de pensamento são percepções dos discursos que os alunos ouvem diariamente. A partir desses discursos, eles formam suas visões de mundo e de natureza, que influenciam e são influenciadas por diversas expressões culturais. Cobern (2000) defende que a visão de mundo inclina as pessoas para um ou outro modo de pensar, consistindo em pressuposições e imagens mentais que possibilitam um modo de compreender o mundo de forma mais ou menos coerente. 
Sobre as influências dos discursos aos quais estão expostos, os alunos da turma A destacaram os radicalismos e posturas que poderiam prejudicar o futuro tecnológico ou de qualidade de vida para o planeta. Para a maior parte dos alunos, o problema estava em como se agiria no futuro e sobre os direitos e deveres humanos e suas consequências. Essa turma citou, nas apresentações dos cartazes em sala, e no trabalho escrito por diversas vezes, o Greenpeace, mas revelaram enxergar os propósitos dessa organização como exagero, despropósito, algo maléfico para as pessoas, denominando os simpatizantes desse movimento de "ecochatos". Por exemplo, na fala do aluno A1: "Existem os que pensam somente na natureza, os famosos 'ecochatos' que são contra qualquer mudança que possa afetar a natureza, nenhuma árvore pode ser derrubada, nenhum animal pode ser morto".

Alguns alunos da mesma turma ficaram mais a favor do equilíbrio em que se preservassem o natural destacado do humano, ou então com equilíbrio e qualidade de vida no espaço urbano mesclado com o natural. Mas, um grupo afirmou que se a natureza está sempre em constante transformação, o homem tem direito a explorá-la e utilizar dela como quiser. Outro grupo, ainda, após descrever as controvérsias atuais, afirmou que muito se fala sobre o tema ambiental, mas que aquilo não representa interesse para nenhum de seus componentes.

As controvérsias atuais que os alunos apontaram sempre tinham a ver com o futuro da natureza, com questões ambientalistas, estivessem eles contra ou a favor delas. No que diz respeito às controvérsias históricas que estavam sendo trabalhadas não apenas nessas atividades, mas nas aulas com contexto histórico-filosófico, a maioria dos alunos, de ambas as turmas, demonstrou compreender o que eram e como funcionavam. Os que compreenderam as controvérsias buscavam traçar um paralelo entre as controvérsias históricas e as atuais que eles reconheciam.

Em todas as atividades ficou bastante evidente que aqueles alunos criaram uma clara distinção, dicotômica e de oposição entre o que é humano versus o natural, tanto na fala quanto nas imagens analisadas. Costumeiramente associaram natureza à presença de vegetação, árvores, rios, montanhas. O brainstorm deixou isso bastante evidente desde o início, em que todos os elementos descritos não tinham nenhuma relação com atividades ou convívio humanos.

\section{3- Natureza e Vida}

Mais do que a distinção entre homens e meio natural, a palavra vida foi utilizada em todas as atividades como sinônimo de natureza. Os alunos não se referiram à vida como qualidade temporária de um organismo, que nasce e morre. O termo "vida" foi igualado à natureza. Para os alunos que participaram desta pesquisa, natureza refere-se ao que é vivo e o não vivo é considerado natureza desde que seja reconhecido como necessário à manutenção da vida. Nesse sentido é que a natureza tem algo em comum com o que é humano: os humanos também precisam do mesmo que a natureza para sobreviver. Se os recursos que promovem a manutenção da vida acabarem, a natureza, literalmente, morre, porque os seres vivos morrerão. 
A natureza pode morrer, portanto, no sentido de que ela é vida porque é composta por seres vivos. Nenhum aluno chegou a mostrar um pensamento diferente desse. Então, uma pedra que não tenha seres vivos associados, não é natureza. E Marte, por exemplo, se os humanos colonizassem esse planeta, seria uma "outra" natureza. Nesse sentido, palavras como vastidão, mistério, colorido, etc, levam em conta especialmente seres vivos, e são esses, exclusivamente, que convivem, interagem e se opõem ao antrópico.

A natureza vista como seres vivos e recursos relacionados à sua manutenção foi uma questão chave para a análise do resultado do projeto. Nos resultados de pesquisas preliminares (autores, 2011), os professores de Física já indicavam essa questão. Eles afirmaram que os alunos só entendiam natureza ligada à Biologia e, portanto, fora do contexto da disciplina Física. Essa dificuldade de abordar natureza nas aulas de Física foi uma controvérsia clara neste trabalho. O termo "vida" usado corriqueiramente como qualitativo ou sinônimo de natural exclui, para os alunos, qualquer tipo de caráter abiótico como natural.

Durante a atividade 3, o ocorrido com a aluna A5 da turma B corrobora essa tendência. A primeira frase do trabalho da referida aluna (que contava com a imagem do pôr do sol na Lagoa Rodrigo de Freitas) foi: "Partindo da definição de natureza como o conjunto de todos os seres que constituem o universo, temos o homem como parte integrante desta, à semelhança dos demais animais". Por ser a primeira aluna a citar o universo, enviamos uma mensagem por e-mail citando a frase dela e questionando: "O que você está considerando como todos os seres? O Ssol e os asteroides entrariam nessa categoria de seres?”. A essa mensagem, a aluna respondeu:

\begin{abstract}
Relendo meu texto compreendo sua dúvida, então, fiz uma pequena alteração no texto para melhor compreensão do que quis dizer, restringindo a definição de natureza ao planeta Terra. Se considero o Sol parte dessa nova definição seria na categoria de elementos que se relacionam à sobrevivência dos seres vivos, fonte de luz e calor. Mesmo que outros elementos 'cósmicos' possam influenciar de alguma forma a vida terrestre (por exemplo, a influência da lua nas marés), não são o foco do argumento que pretendia construir. $\mathrm{O}$ ponto principal é a inclusão do homem no conceito de natureza.
\end{abstract}

Ao reescrever seu texto a aluna alterou o primeiro e no lugar de universo escreveu: "o conjunto de todos os seres vivos que constituem o planeta e os elementos que constituem a sua sobrevivência como a água, o ar, o solo etc". Ou seja, para a aluna, o homem é parte constitutiva da natureza não pela origem ou por qualidades outras senão por ser vivo, e qualquer fator abiótico existe para permitir a vida. Qualquer outro elemento não vivo e que não seja essencial à vida não é natural.

Como o termo "vida" foi utilizado amplamente nos trabalhos como uma qualidade que define natureza, essa palavra foi, em todas as atividades, classificada como um qualisigno; enquanto "seres vivos", termo que sempre apontava para a presença de vegetais e animais outros que não o homem, foi classificado como sinsigno. 
Esse resultado revela uma controvérsia histórica que não foi possível de ser trabalhada com maior profundidade nesse projeto: a controvérsia do conceito de vida do século XIX. Ao estudar sobre mecanicismo e naturphilosophie, os alunos foram apresentados a dois diferentes conceitos de vida. No entanto, esses não eram os únicos conceitos de vida que eram debatidos naquele século. Além de ter sido palco do debate entre o que é a natureza e o papel do homem, o século XIX foi o século de estruturação da ciência que estuda a vida, a Biologia. O debate sobre o que consistia a vida e os elementos que a compunham, se seriam ou não apenas físico-químicos, eram muito mais intensos do que o trabalhado no curto período das atividades aqui descritas. A primeira metade do século XIX foi rica em filosofias do que é vida, como o organicismo, o vitalismo, e o monismo (CORREA et al., 2008).

\section{COMENTÁRIOS FINAIS}

Cada turma teve suas características particulares influenciadas pelas suas individualidades, mas também pela sua experiência mais ou menos recente num curso com abordagem histórico-filosófica. A turma A, que estudou Física através de um enfoque histórico-filosófico desde o primeiro ano do Ensino Médio, teve uma postura muito mais crítica aos discursos ambientais que a $\mathrm{B}$, que não teve esse tipo de ensino anteriormente. Mas, ambas as turmas apresentaram dificuldades em trabalhar com imagens. A preocupação ambiental dos alunos pareceu sempre voltada aos discursos midiáticos e aos problemas que eles veem na televisão.

As imagens históricas demonstraram ser um bom caminho para, no ensino de ciências, mesclar abordagem histórico-filosófica e imagem. As imagens são fontes primárias por meio das quais o aluno pode entrar em mais ou menos detalhes, conforme sua capacidade, e ao mesmo tempo aprender o conteúdo. Fontes primárias escritas são mais restritivas nesse sentido (BURKE, 2004).

O projeto foi completamente voltado para os pontos que os alunos levantaram. As atividades foram construídas e transformadas de acordo com a demanda deles. E, com isso, alguns pontos relevantes das controvérsias sobre a relação homem versus natureza, do começo do século XIX, não foram contempladas como a questão da escravidão, a questão rural e econômica brasileira, desmatamento e monoculturas, industrialização e formação de grandes centros urbanos, problemas sanitários, de saúde e sociais, as grandes ideologias, etc. Nenhum desses pontos teve grande expressão ou preocupação por parte dos alunos e, dentro dos objetivos propostos, seguimos os elementos que recebemos. Além disso, havia um tempo reduzido para um esforço grande em contemplar tantos assuntos.

O recorte no período histórico se mostrou profícuo, possibilitando discutir visões de natureza nas aulas de Física. Importante, ainda, destacar que o trabalho permitiu trazer as controvérsias históricas e seus impactos na cidade onde vivem os alunos, aproximando-os ainda mais do conteúdo estudado. 
Certamente existem outras formas de trabalhar a relação homem versus natureza nas outras ciências naturais. Os resultados desta pesquisa apontam que um bom ponto de partida é problematizar a questão de vida como sinônimo de natureza. A ideia de natureza como limitada ao que é vivo e ao que permite a vida é apenas um dos diversos modos de entender o mundo natural, e cabe ao professor apresentar outras formas para os alunos. Quanto mais acesso a diferentes visões das suas o aluno tiver, maiores as chances de se tornar um cidadão crítico e tomar decisões conscientes quanto ao meio ambiente.

Quanto aos elementos que foram identificados com o presente trabalho, os alunos se mostraram diversos em tipos semióticos com os quais trabalharam. Embora tenha havido em um primeiro momento tendências nas turmas, de qualisigno para a turma $\mathrm{A}$ e legisigno na $\mathrm{B}$, ao fim do trabalho essas tendências mudaram. Isso significa que os alunos fizeram um esforço e buscaram novos argumentos.

De acordo com Santaella (2005) mais perfeita será a semiose quanto mais tipos diferentes de signos forem usados. E analisando os resultados, é notável que os signos ficaram mais diversos ao fim das atividades que no começo. Para Peirce (2010), a construção do signo é coletiva, então o debate e a troca de informações a respeito das imagens históricas parece ter contribuído para a ação do signo-semiose. Nesse sentido, conseguimos aprofundar a ação do signo "natureza", tornando-o mais diverso e ampliando seus sentidos.

\section{REFERÊNCIAS}

ALLCHIN, D. "Pseudohistory and Pseudoscience". Science \& Education v.13:179 - 195. 2004.

BOGDAN, R.C.; BIKLEN, S.K. Investigação Qualitativa em Educação. Porto: Porto editora, 1994.

BOWLER, P. J. "Malthus, Darwin, and the Concept of Struggle". Journal of the History of Ideas, vol. 37, n. 4, p. 631-650. Oct. - Dec., 1976.

BRAGA, M.; GUERRA, A.; REIS; J.C. "The Role of Historical-Philosophical Controversies in teaching Sciences: The Debate Between Biot and Ampere.” Science\& Education, v. 21.6, p. 921-934. 2012.

BURKE, P. Testemunha Ocular: história e imagem. Bauru, SP: EDUSC, 2004. 270 p.

CAMPONOGARA, S.; RAMOS, F. R. S.; KIRCHHOF, A. L. C. Reflexões sobre o conceito de natureza: aportes teórico-filosóficos. Revista Eletrônica do Mestrado em Educação Ambiental, Rio Grande, RS, v.18, p. 1-19. 2007.

CANEVA, K. 'Physics and Naturphilosophie: a reconnaisance'. History of Science, v.35, p. 35-106, jan./jun. 1997.

COBERN, W. W. Everyday Thoughts about Nature. Dordrecht: Kluwer, 2000.

COSTA, P.F.C. A visualização da natureza e o entendimento do mundo vivo. Filosofia e História da Biologia, São Paulo, v. 1, p. 247-269, 2006.

CORREA, A. L. et al. Aspectos históricos e filosóficos do conceito de vida: contribuições para o ensino de biologia. Filosofia e História da Biologia, São Paulo, v.3(1), p.21-40, 2008.

ERMAKOFF, G. Paisagem do Rio de Janeiro: aquarelas, desenhos e gravuras dos artistas viajantes 1790-1890. Rio de Janeiro: G.Ermakoff editorial. 2011. 408 p.

FLICK, U. Introdução a Pesquisa Qualitativa. 3. ed. Porto Alegre: Artmed, 2009.

FORATO, T.C.M.; MARTINS, R. A.; PIETROCOLA, M. History and Nature of Science in High 
School: Building Up Parameters to Guide Educational Materials and Strategies. Science \& Education, v.21, p. 657-682, 2012.

GALIMBERTI, U. Psiche e Techne: o homem na idade da técnica. São Paulo: Paulus. 2006.

JAPPY, T. Introduction to Peircean Visual Semiotics. Bloomsbury Advances in Semiotics. Chennai, India: ed. Bloomsberry Academic Publishing, 2013.

LENOBLE, R. História da ideia de naturęa. Lisboa: Ed.70,1999.

MARTINS, L. The art of tropical travel, 1768-1830, in: M. Ogborn and C. Withers (Eds), Georgian Geographies: Essays on Space, Place, and Landscape in the Eighteenth Century. Manchester: s.n, 2004. pp. 72-91.

MCCOMAS, W. F. Seeking historical examples to illustrate key aspects of the nature of science. Science \& Education, Dordrecht, Holanda, v.17, n.2, p 249-263. 2008.

PEIRCE, C. S. Semiótica. São Paulo: Perspectiva, 2010.

QUEIROZ, João. Introdução à divisão 3-tricotômica de signos. Cadernos de Estudos Lingüísticos, Campinas, v. 46, n. 2, 2011.

RAMINELLI, R. Vistas e Paisagens: imagens do Rio de Janeiro Colonial. Revista da História, São Paulo, vol 147, p. 33-52, 2002.

RAMOS, M. B. ; SILVA, H. C. Para pensar as controvérsias científicas em aulas de ciências. In: Ciência \& Ensino, vol. 1, número especial, 2007.

REIS, J. C.; GUERRA, A.; BRAGA, M.; “Ciência e arte: relações improváveis?” História, Ciências, Saúde, Manguinhos, v. 13 (suplemento), p. 71-87, out. 2006.

ROUILLÉ, A. A fotografia: entre documento e arte contemporânea. São Paulo: Editora Senac 2009.

SANTAELLA, L. Matriz̧es da Linguagem e Pensamento: sonora, visual e verbal - aplicações na hipermídia. 3 ed. São Paulo: Iluminuras, 2005.

. Semiótica Aplicada. São Paulo: Ed. Cengage Learning, 2012.

SCHWARCZ, L.M. O Sol do Brasil: Nicholas-Antoine Taunay e as desventuras dos artistas franceses na corte de d. João. São Paulo: Companhia das Letras, 2008.

TUCKER, J. The historian, the picture, and the archive. Isis, Chicago, EUA, v. 97, n. 1, p. $111-$ 120, 2006.

Data Recebimento: 23/12/2013

Data Aprovação: 14/03/2014

Data Versão Final: 5/04/2014

\section{Contato:}

Centro Federal de Educação Tecnológica de Celso Suckow da Fonseca CEFET/RJ. Diretoria de Pesquisa e Pós-Graduação . DIPPG/PPCTE

Av. Maracanã, $229 \cdot 5^{0}$ andar - sala E-503-14 - Maracanã - Rio de Janeiro, RJ - Brasil

CEP: 20271-110 
